\title{
Copper Levels in Patients with Unexplained Dysplastic Cytopenia
}

\author{
Dominic Butcher ${ }^{1}$ (D) $\cdot$ Simona Deplano ${ }^{2} \cdot$ Thomas Lofaro $^{2}$ (I)
}

Received: 17 March 2020 / Accepted: 14 May 2020 / Published online: 2 June 2020

(C) The Author(s) 2020

\begin{abstract}
Copper deficiency can produce changes mimicking myelodysplasia, but its prevalence among haematology patients is unknown. This study evaluates the prevalence of deficiency in a population of patients with unexplained cytopenia(s) and dysplasia. Of 17 patients recruited, only one was found to have a low copper level. This is the first study evaluating hypocupremia in patients with isolated haematological manifestations. Our results suggest that copper deficiency is uncommon in this population, and the routine measurement of copper seems unlikely to be cost-effective. We recommend a risk-assessed approach to testing based on the identification of risk factors and of signs suggestive of deficiency.
\end{abstract}

Keywords Copper $\cdot$ Myelodysplasia $\cdot$ MDS $\cdot$ Cytopenia $\cdot$ Dysplasia $\cdot$ Hypocupremia

\section{Introduction}

Copper is an essential micronutrient that is incorporated into copper-dependent enzymes and plays an integral role in oxidation-reduction reactions. Several risk factors for copper deficiency are reported in the literature, and hypocupremia can present with a variety of metabolic, haematological and neurological manifestations (Fig. 1). To the haematologist, copper deficiency can present with signs of bone marrow failure and dysplastic haematopoiesis [1,2], and can be misdiagnosed as myelodysplastic syndrome (MDS) [3].

There is uncertainty regarding the role of copper measurement in patients with unexplained cytopenia. The prevalence of copper deficiency among unselected patients is unknown [6], and the only data available is in select groups of patients $[6,14]$. Myelodysplasia (MDS) is an important differential of copper deficiency, and is characterised by cytopenia(s), dysplastic haematopoiesis and an increased risk of transformation to acute leukaemia. Under the microscope, copper deficiency

Electronic supplementary material The online version of this article (https://doi.org/10.1007/s12011-020-02203-x) contains supplementary material, which is available to authorized users.

Dominic Butcher

dominic.butcher15@imperial.ac.uk

1 Department of Medicine, Imperial College London, South Kensington, London, UK

2 Imperial College NHS Healthcare Trust, Department of Haematology, Hammersmith Hospital, Du Cane Road, London, UK may uniquely produce vacuolation in the myeloid precursors, and this finding should prompt consideration for this differential. Pelger-Huet neutrophils, dysmegakaryopoiesis and an excess of blasts, on the other hand, favour a diagnosis of MDS [15].

Cytogenetic and molecular analysis are able to demonstrate evidence of clonal haematopoiesis in $75 \%$ of patients with MDS [16], and this raises the question of whether other pathology may be present in those patients in whom no clonal marker is found. Possible precursor conditions for MDS also need to be considered in the differential diagnosis, including idiopathic cytopenia of uncertain significance (ICUS) and idiopathic dysplasia of uncertain significance (IDUS). ICUS is characterised by persistent unexplained cytopenia of more than 6 months' duration, with dysplastic features absent or only visible in less than $10 \%$ of cells in each cell line. IDUS is a condition with dysplastic features in excess of $10 \%$ in one or more cell lines but without significant cytopenia, and with or without genetic or molecular markers of clonality.

MDS should only be diagnosed when other causes of the haematological features have been excluded. A diagnosis of MDS has significant implications for patients, not least because of the known risk of progression to leukaemia. If an alternative cause is missed, patients will be subjected to needless investigations and hospital appointments, and will also be at risk of developing complications of their condition that could have been prevented with appropriate treatment.

We designed a study to evaluate the prevalence of copper deficiency in patients with cytopenias and dysplasia who also lack a cytogenetic or molecular marker of MDS. The participants were all patients who were being monitored in our 


\section{Risk Factors}
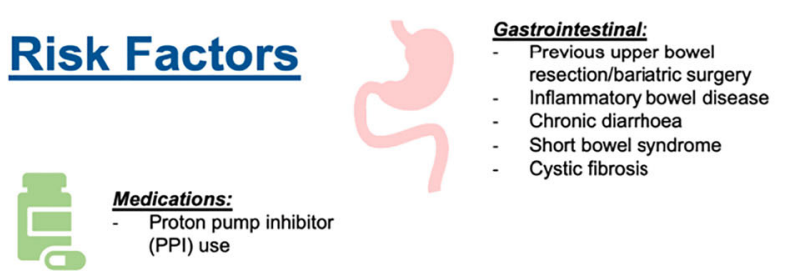

Medications: Proton pump inhibitor (PPI) use

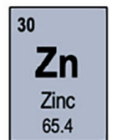

Excess Zinc: Overuse of zinc supplements Ingestion of dental fixatives Treatment of Wilson's disease
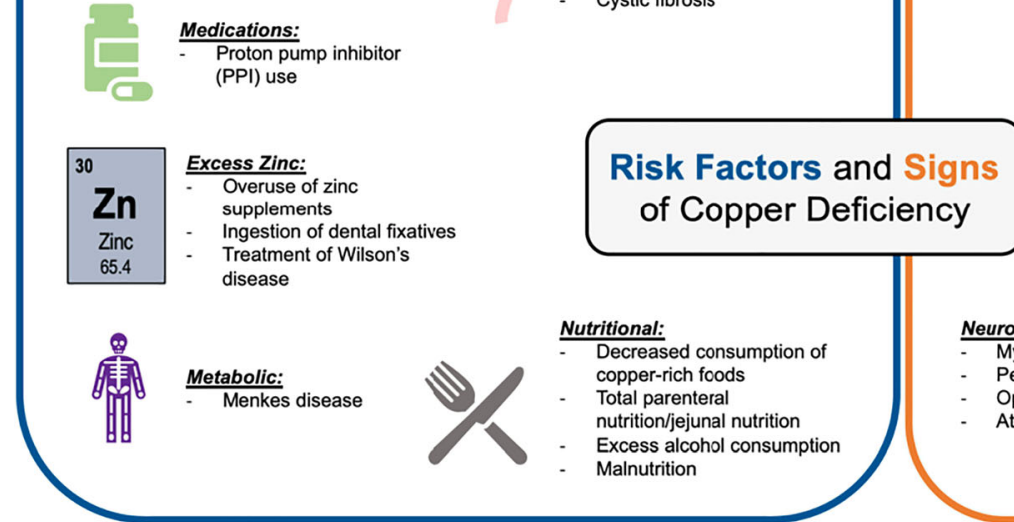

Cardiovascular: Hypercholesterolaemia Ischaemic heart diseas Stroke

Myocardial infarction

Sudden death

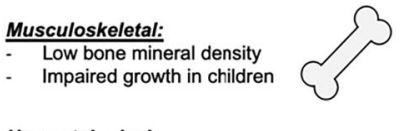

Haematological: Anaemia Leucopenia Thrombocytopeni Dysplastic haematopoiesis with or without ring sideroblasts
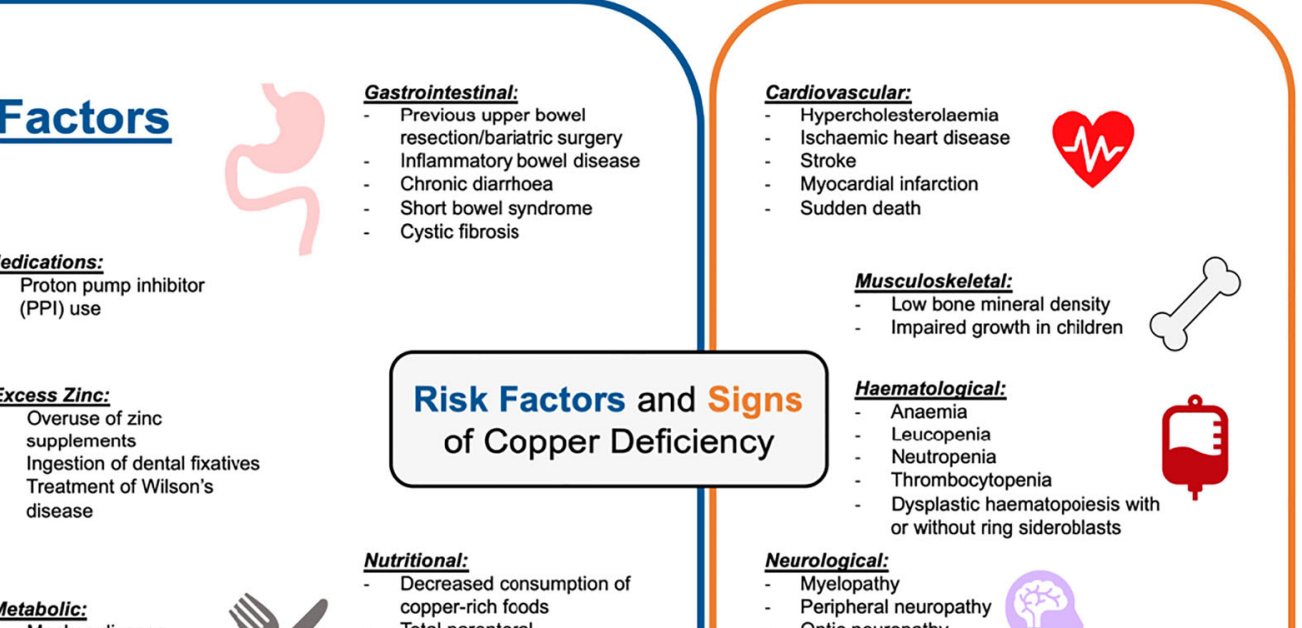

Menkes disease

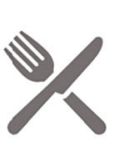

Nutritional:

Decreased consumption of

copper-rich foods

Total parenteral

nutrition/jejunal nutrition

Excess alcohol consumption

Malnutrition

Fig. 1 The risk factors for and signs of copper deficiency. Please see references: risk factors $[1,2,4-11]$ and signs $[1,2,9,12,13]$

haematology clinic. The majority had bone marrow dysplasia reported in excess of $10 \%$, and therefore fulfilled WHO criteria for a diagnosis of myelodysplasia.

\section{Methods}

We evaluated our clinic and bone marrow records to identify potential participants. We wanted to exclude patients in whom a true diagnosis of MDS was highly likely. To achieve this, we excluded patients with a confirmed cytogenetic or molecular abnormality (with the exception of deletion of chromosome Y), those with a marrow blast percentage in excess of $5 \%$ on cytological examination or immunophenotyping, and patients who were receiving (or had previously received) cytotoxic treatment for MDS.

We identified 17 potential patients who met our inclusion criteria (ESM 1). Eligible patients were offered information about the study and invited to participate. All 17 patients gave consent. As part of the study, patients were asked to complete a health questionnaire (ESM 6) and to submit a blood test for measurement of their serum copper level. The questionnaire was designed to identify risk factors for the development of copper deficiency and included questions about diet, drug history, the use of mineral supplements, gastrointestinal pathology, bowel surgery, dialysis and alcohol intake. Additional questions were included to identify unexpected symptoms of the condition.

Mutation screening in our centre is performed by targeted next generation sequencing using TruSight Myeloid panel (Illumina) using the Qiagen QIAsymphony DSP DNA Mini Kit. This assay comprises of 568 amplicons in 54 genes frequently mutated in myeloid malignancies, including mutations in ABL1, ASXL1, ATRX, BCOR, BCORL1, BRAF, $C A L R, C B L, C B L B, C B L C, C D K N 2 A, C S F 3 R, C E B P A$, CUX1, DNMT3A, ETV6, EZH2, FBXW7, FLT3, GATA1, GATA2, GNAS, HRAS, IDH1, IDH2, IKZF1, JAK2, JAK3, KDM6A, KIT, KRAS, MLL, MPL, MYD88, NOTCH1, NPM1, NRAS, PDGFRA, PHF6, PTEN, PTPN11, RAD21, RUNX1, SETBP1, SF3B1, SMC1A, SMC3, SRSF2, STAG2, TET2, TP53, U2AF1, WT1, and ZRSR2. The software used for analysis was Variant Interpreter (Illumina; Version 2.4.2.2846).

\section{Results}

The demographic data of our population and full blood count results at study inclusion are summarised in ESM 2 and ESM 3. All patients, bar one, had a bone marrow examination as part of their investigations, and mutation analysis had consequently been carried out on bone marrow in 16 of the participants. Dysplasia in excess of $10 \%$ in one or more cell lines was reported on the bone marrow in 11 patients and there was no evidence of other bone marrow disease in any of the specimens. Four patients had a diagnosis of ICUS, while the remaining 12 patients had received a diagnosis of MDS. One patient had refused a bone marrow, so had mutation analysis on peripheral blood. This patient was an 81-year-old lady who was being monitored for persistent anaemia. She had an abnormal blood film with dysplastic features in the red cells and neutrophils, as well as notable platelet anisocytosis. None of the patients had been found to have a cytogenetic or a molecular abnormality when tested.

All participants completed the health questionnaire. Relevant data for each patient is displayed in ESM 4. Risk 
factors for copper deficiency were identified in ten patients, but none of these patients had copper levels below the reference range (ESM 5). One patient was found to have a low serum copper level, marginally below the reference range $(11.3 \mu \mathrm{mol} / \mathrm{L}-$ reference range $12 \mu \mathrm{mol} / \mathrm{L}$ to $20 \mu \mathrm{mol} / \mathrm{L})$. This was a 79-year-old Indian male who was being monitored for pancytopenia with dysplastic changes (reported to be in excess of 10\%) in the erythroid and megakaryocytic lineages. He had been given a diagnosis of MDS. The patient did not report any risk factors for copper deficiency and there was no other comorbidity to suggest this diagnosis. The patient was offered copper replacement but failed to return to clinic for a prescription.

Interestingly, six patients (33\%) had copper levels which were mildly above the reference range. Inflammation has been documented to produce a reactive rise in plasma copper level [17], and we therefore tested levels of C-reactive protein (CRP) to clarify the significance of these results. Two patients had elevated CRP levels at the time of testing (patient 14-CRP $32.5 \mathrm{mg} / \mathrm{L}$; patient $15-\mathrm{CRP} 58.8 \mathrm{mg} / \mathrm{L}$; reference range 0 $5 \mathrm{mg} / \mathrm{L}$ ), so the elevated copper level in these patients is likely to be spurious. Four patients had CRP levels that were within the reference range (patients 12,13,16 and 17; CRP values $1.4,0.3,3.9$ and $2.4 \mathrm{mg} / \mathrm{L}$, respectively). The marginally elevated copper level in these patients remains unexplained.

\section{Discussion}

Measuring copper levels has been reported as an important part of the workup when investigating patients with unexplained cytopenias [13]. The burden of misdiagnosing copper deficiency as MDS may be significant for both the patient and the healthcare provider. While studies in patients with a history of bariatric surgery and with neurological manifestations did include patients with cytopenia(s) $[6,14]$, our study is the first to evaluate the prevalence of copper deficiency in a population of patients presenting with predominantly haematological manifestations to a haematology clinic. The majority of our patients fulfilled WHO diagnostic criteria for MDS, and all lacked a genetic or molecular marker of clonality.

Myelodysplasia is an uncommon condition with only 1524 new cases reported nationwide in England in 2017 [18]. Our study has limitations, particularly its small size and singlecentre recruitment design. In addition, we are unable to report on the response to copper replacement in our one patient who was found to have low levels because he failed to engage further with our services. On the other hand, our study has strength in its partially prospective design and the inclusion of a health questionnaire to screen for unanticipated risk factors.
Our results suggest that copper deficiency is uncommon in this population of patients, although one must be cautious in drawing conclusions due to the small size of our population. We were not able to demonstrate a relationship between the identification of risk factors for copper deficiency and copper levels, and this is almost certainly because of the low number of positive findings. It is not likely that the low copper level in one of our patients was contributing to his haematological features because his copper level was only a fraction outside the reference range, and he had a normal CRP $(0.6 \mathrm{mg} / \mathrm{L})$ at the time of testing. This suggests his copper level was not falsely raised to mask a more severe deficiency.

While copper deficiency should be considered in the differential diagnosis of cytopenias and dysplasia, our findings lead us to believe that indiscriminate testing of copper levels in patients with unexplained cytopenia may not be cost-effective. Based on data from larger studies, the identification of risk factors for the condition and signs of deficiency should improve the likelihood of a positive diagnosis $[7,9,14]$. We would recommend the consideration of copper deficiency in the differential of persistent cytopenias, and we suggest a risk-assessed approach to testing that seeks to identify patients who may be more likely to have this rare diagnosis.

Acknowledgements We would like to thank all the participants. Also, a thank you to the staff in the Haematology Department at Hammersmith Hospital who helped to facilitate our research.

Authors' Contributions Dominic Butcher contributed to the design of the research, recruitment of participants, collection of data, and was the principal author. Simona Deplano contributed to the design of the study and the writing of the paper. Thomas Lofaro designed the study and contributed to the recruitment of participants, collection of data and the writing of the paper. All authors read and approved the final manuscript.

Funding Information This study was sponsored by Imperial College London.

Data Availability All data generated or analysed during this study are included in this published article (and its supplementary information files).

\section{Compliance with Ethical Standards}

Conflict of Interest The authors declare that they have no conflict of interest.

Ethics Approval All procedures performed involving human participants were in accordance with the ethical standards of the national research committee and with the 1964 Helsinki declaration and its later amendments or comparable ethical standards. The study design was approved by London Riverside Research Ethics Committee.

Consent to Participate Informed consent was obtained from all individual participants included in the study. 
Open Access This article is licensed under a Creative Commons Attribution 4.0 International License, which permits use, sharing, adaptation, distribution and reproduction in any medium or format, as long as you give appropriate credit to the original author(s) and the source, provide a link to the Creative Commons licence, and indicate if changes were made. The images or other third party material in this article are included in the article's Creative Commons licence, unless indicated otherwise in a credit line to the material. If material is not included in the article's Creative Commons licence and your intended use is not permitted by statutory regulation or exceeds the permitted use, you will need to obtain permission directly from the copyright holder. To view a copy of this licence, visit http://creativecommons.org/licenses/by/4.0/.

\section{References}

1. Villalba A, Senent L (2018) Differential diagnosis of myelodysplastic syndrome: anemia associated with copper deficiency. Blood 131(12):1389. https://doi.org/10.1182/blood-201711-818013 Available from: [Accessed Mar 1, 2019]

2. Myint Z, Oo T, Thein K, Tun A, Saeed H (2018) Copper deficiency anemia: review article. Ann Hematol 97(9):1527-1534. https://doi. org/10.1007/s00277-018-3407-5 Available from: https://www. ncbi.nlm.nih.gov/pubmed/29959467 [Accessed Mar 4, 2019]

3. Kumar N, Elliott MA, Hoyer JD, Harper CM, Ahlskog JE, Phyliky RL (2005) "Myelodysplasia," myeloneuropathy, and copper deficiency. Mayo Clin Proc 80(7):943-946. https://doi.org/10.4065/80. 7.943 Available from: https://www.mayoclinicproceedings.org/ article/S0025-6196(11)61571-1/fulltext [Accessed Mar 10, 2019]

4. Halfdanarson TR, Kumar N, Li C, Phyliky RL, Hogan WJ (2008) Hematological manifestations of copper deficiency: a retrospective review. Eur J Haematol 80(6):523-531. https://doi.org/10.1111/j. 1600-0609.2008.01050.x Available from: https://onlinelibrary. wiley.com/doi/abs/10.1111/j.1600-0609.2008.01050.x [Accessed Mar 4, 2019]

5. Shibazaki S, Uchiyama S, Tsuda K, Taniuchi N (2017) Copper deficiency caused by excessive alcohol consumption. BMJ Case Rep 2017:bcr-220921. https://doi.org/10.1136/bcr-2017-220921 Available from: [Accessed Mar 4, 2019]

6. Gabreyes AA, Abbasi HN, Forbes KP, McQuaker G, Duncan A, Morrison I (2013) Hypocupremia associated cytopenia and myelopathy: a national retrospective review. Eur J Haematol 90(1):1-9. https://doi.org/10.1111/ejh.12020 Available from: https:// onlinelibrary-wiley-com.iclibezp1.cc.ic.ac.uk/doi/full/10.1111/ejh. 12020 [Accessed Mar 18, 2019]

7. Duncan A, Yacoubian C, Watson N, Morrison I (2015) The risk of copper deficiency in patients prescribed zinc supplements. J Clin Pathol 68(9):723-725. https://doi.org/10.1136/jclinpath-2014202837 Available from: [Accessed Mar 4, 2019]

8. Cortese A, Zangaglia R, Lozza A, Piccolo G, Pacchetti C (2011) Copper deficiency in Wilson's disease: peripheral neuropathy and myelodysplastic syndrome complicating zinc treatment. Mov Disord 26(7):1361-1362. https://doi.org/10.1002/mds.23520
Available from: https://onlinelibrary.wiley.com/doi/abs/10.1002/ mds.23520 [Accessed Mar 7, 2019]

9. Jaiser SR, Winston GP (2010) Copper deficiency myelopathy. J Neurol 257(6):869-881. https://doi.org/10.1007/s00415-0105511-x Available from: https://www.ncbi.nlm.nih.gov/pmc/ articles/PMC3691478/ [Accessed Mar 11, 2019]

10. Plantone D, Renna R, Primiano G, Shukralla A, Koudriavtseva T (2015) PPIs as possible risk factor for copper deficiency myelopathy. J Neurol Sci 349(1):258-259. https://doi.org/10.1016/j.jns. 2015.01.009 Available from: http://www.sciencedirect.com/ science/article/pii/S0022510X15000106 [Accessed May 7, 2019]

11. Wazir SM, Ghobrial I (2017) Copper deficiency, a new triad: anemia, leucopenia, and myeloneuropathy. J Community Hosp Intern Med Perspect 7(4):265-268. https://doi.org/10.1080/20009666. 2017.1351289 Available from: https://www.ncbi.nlm.nih.gov/ pubmed/29046759 [Accessed Mar 7, 2019]

12. Qu X, He Z, Qiao H, Zhai Z, Mao Z, Yu Z et al (2018) Serum copper levels are associated with bone mineral density and total fracture. J Orthop Translat 14:34-44. https://doi.org/10.1016/j.jot. 2018.05.001 Available from: [Accessed Mar 25, 2019]

13. Karri S, Doshi V (2007) Hematological abnormalities in copper deficiency. Blood 110(11):2677. https://doi.org/10.1182/blood. V110.11.2677.2677 Available from: https://doi.org/10.1182/ blood.V110.11.2677.2677 [Accessed 10/24/2019]

14. Gletsu-Miller N, Broderius M, Frediani JK, Zhao VM, Griffith DP, Davis SS et al (2012) Incidence and prevalence of copper deficiency following Roux-en-y gastric bypass surgery. Int J Obes 36(3): 328-335. https://doi.org/10.1038/ijo.2011.159 Available from: [Accessed Mar 18, 2019]

15. Lazarchick J (2012) Update on anaemia and neutropenia in copper deficiency. Curr Opin Hematol 19(1):58-60. https://doi.org/10. 1097/MOH.0b013e32834da9d2 Available from: [Accessed Mar $18,2019]$

16. Hou H, Tsai C, Lin C, Chou W, Kuo Y, Liu C et al (2018) Incorporation of mutations in five genes in the revised International Prognostic Scoring System can improve risk stratification in the patients with myelodysplastic syndrome. Blood Cancer J 8(4):39-13. https://doi.org/10.1038/s41408-018-0074-7 Available from: [Accessed May 10, 2019]

17. Tsuboi A, Terazawa Watanabe M, Kazumi T, Fukuo K (2014) Serum copper, zinc and risk factors for cardiovascular disease in community-living Japanese elderly women. Asia Pac J Clin Nutr 23(2):239-245. https://doi.org/10.6133/apjen.2014.23.2.04 Available form: [Accessed May 10, 2019]

18. Office for National Statistics. Cancer registration statistics, England. Available from: https://www.ons.gov.uk/ peoplepopulationandcommunity/healthandsocialcare/ c o n d i t i o n s a nd d is e a s e s/dat a s e t s/ cancerregistrationstatisticscancerregistrationstatisticsengland [Accessed Apr 28, 2020]

Publisher's Note Springer Nature remains neutral with regard to jurisdictional claims in published maps and institutional affiliations. 